\title{
Association between electromyographic localized muscle fatigue of the rectus femoris and static postural balance in physically active adult men
}

\section{Associação entre fadiga muscular localizada eletromíográfica do reto femoral e equilíbrio postural estático em homens adultos fisicamente ativos}

\author{
Mariam Mian Bouchnak \\ (D) https://orcid.org/0000-0003-2962-2375 \\ Thatiane Lopes Valentim Di Paschoale Ostolin ${ }^{1}$ \\ (i) https://orcid.org/0000-0002-8492-2840 \\ Evandro Fornias Sperandio ${ }^{1}$ \\ (D) https://orcid.org/0000-0002-8580-458X \\ Wesley de Oliveira Vieira ${ }^{1}$ \\ (D) https://orcid.org/0000-0002-1313-5567 \\ Victor Zuniga Dourado \\ (D) https://orcid.org/0000-0002-6222-3555
}

Abstract - Although the determinant impact of exercise-induced muscle fatigue prior to postural balance assessment has been widely described, recent evidence suggests that hyperventilation and sensorimotor losses, rather than muscle fatigue, are responsible for the changes observed in postural balance. However, the association between localized muscle fatigue (LMF), induced by isokinetic dynamometer protocol test and assessed through surface electromyography, and postural balance in adults is poorly understood. We aimed to evaluate the association between the LMF of the rectus femoris and static postural balance in 51 adult men $(43 \pm 14.8$ years; $\left.26.9 \pm 5 \mathrm{~kg} / \mathrm{m}^{2}\right)$. We obtained physical activity level and postural balance, respectively, through a triaxial accelerometry and a force platform. The quadriceps femoris strength and endurance were obtained using an isokinetic dynamometer and surface electromyography simultaneously. The association between the isokinetic and electromyographic LMF and static postural balance was investigated using linear regression models adjusted for age, body mass index, and isokinetic quadriceps strength and LMF. The correlations between postural balance variables and isokinetic muscle strength and LMF were weak-to-moderate. After multivariate analyses, we observed that electromyographic LMF were a predictor of postural balance, mainly of the mean amplitude and center of pressure area and velocity in the mediolateral direction, regardless of isokinetic variables. Therefore, LMF plays a determinant role in the postural balance of physically active adult men. Fatigue indices are significant predictors of postural balance, regardless of previous fatigue induction.

Key words: Electromyography; Fatigue; Muscle strength; Postural balance.

Resumo - Embora o impacto da fadiga muscular induzida antes da avaliação do equilíbrio postural tenha sido amplamente descrito, evidências recentes sugerem que hiperventilação e perdas sensório- motoras, ao invés de fadiga, são responsáveis por alterações no equilibrio postural. Contudo, a associação entre fadiga muscular localizada (FML), induzida por protocolo de teste em dinamômetro isocinético e avaliada por meio de eletromiografia de superfície, e equilíbrio postural em adultos é pouco compreendida. Investigamos a associação entre FML do músculo reto femoral e equilibrio pos-

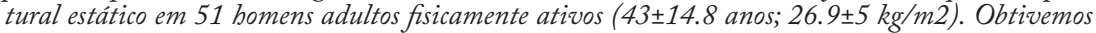
atividade física habitual e equilibrio postural, respectivamente, por meio de acelerometria triaxial e plataforma de força. A força e endurance musculares do músculo quadriceps femoral foram obtidas através de dinamometria isocinética e eletromiografia de superfície simultaneamente avaliadas. $A$ associação entre a FML eletromiográfica e isocinética e o equilíbrio postural foi investigada por meio de modelos de regressão linear ajustados por idade, indice de massa corporal, força isocinética e FML eletromiográfica do quadriceps. As correlaçóes entre equilibrio postural, força isocinética e FML foram fracas a moderadas. Após análise multivariada, FML eletromiográfica foi determinante para equilibrio postural, sobretudo para amplitude média e área e velocidade do centro de pressão na direção mediolateral, independente das variáveis isocinéticas. Portanto, FML apresenta papel determinante no equilibrio postural de homens adultos fisicamente ativos. Os indices de fadiga são preditores significativos do equilibrio postural, independente de indução da fadiga.

Palavras-chave: Eletromiografia; Equilíbrio postural; Fadiga; Força muscular.
1 Federal University of São Paulo. Department of Human Movement Sciences. Santos, SP. Brazil.

Received: July 03, 2019 Accepted: June 25, 2020

How to cite this article Bouchnak MM, Ostolin TLVDP, Sperandio EF, Vieira WO, Dourado VZ. Association between electromyographic localized muscle fatigue of the rectus femoris and static postural balance in physically active adult men. Rev Bras Cineantropom Desempenho Hum 2020, 22:e66062. DOl: http://dx.doi.org/10.1590/19800037.2020v22ef6062

Copyright: This work is licensed under a Creative Commons Attribution 4.0 International License. 


\section{INTRODUCTION}

Localized muscle fatigue (LMF) is defined as an exercise-induced reduction in the ability of a muscle to generate force or power, regardless of the ability to sustain the task $\mathrm{k}^{1,2}$. LMF is a complex and multifactorial phenomenon that is widely used as an indicator of physiological processes since fatigue leads to a decline in the desired performance and capacity to produce muscle strength during various efforts ${ }^{2,3}$.

Unlike muscle strength ${ }^{4}$, the association between LMF and postural balance in adults is poorly understood. Acute induction of muscle fatigue by specific protocols of high-intensity exercises negatively affects the postural balance in both adults and older adults ${ }^{5,6}$. However, recent evidence suggests that hyperventilation rather than muscle fatigue is responsible for changes in postural balance during the induction of fatigue by intense short-term exercise ${ }^{7}$. Even in exercises with different intensities that induce different levels of hyperventilation, postural balance impairment was identified ${ }^{7,8}$. In addition to hyperventilation, sensorimotor losses may also play a determining role in postural balance ${ }^{7,8}$. Considering that other physiological mechanisms can also influence postural balance after fatigue induction protocols, it is essential to investigate the extent to which LMF determine the postural balance in adults.

A variety of methods have been used to measure LMF. However, the ability to sustain a load or increase the force level can be subjectively modified (e.g., through motivation) ${ }^{9}$. Accordingly, surface EMG has been considered a reliable method to evaluate LMF since the changes in the EMG median frequency during sustained isometric contraction or successive dynamic contractions is a physiological manifestation of $\mathrm{LMF}^{9,10}$. Additionally, LMF can also be investigated by mechanical methods including successive contractions in an isokinetic dynamometer ${ }^{11}$.

Therefore, intrinsic and extrinsic fatigue measures combined (e.g., isokinetic dynamometry and EMG) may allow a better understanding of the association between LMF and postural balance. The evaluation of rectus femoris is rational since it is widely used in daily living activities, as well as often recruited to maintain orthostatic posture and move from sitting to standing ${ }^{12}$.

We hypothesized that LMF of the rectus femoris, induced by isokinetic dynamometer protocol test and assessed through EMG, is a determinant of static postural balance in physically active adult men. If confirmed, we can elucidate this association free of the confounding effect of other physiological attributes related to the acute induction of muscular fatigue and, hence, to provide evidence for designing interventions to improve LMF and postural balance.

The primary objective of the present study was to evaluate the association between the electromyographic LMF of the rectus femoris and the static postural balance in physically active adult men. 


\section{METHODS}

\section{Study design and participants}

We conducted a cross-sectional study with 51 physically active, healthy men aged 20 to 80 years. Participants were recruited through ads on social networks, magazines, and newspapers, and at local universities.

The Human Research Ethics Committee of the Federal University of São Paulo (no. 0968/2016) approved this study. All volunteers were informed about the risks and discomforts related to the evaluation protocol and gave their written consent.

We conveniently included only physically active male participants free of cardiorespiratory and locomotor diseases. The exclusion criteria were the use of walking aids or difficulties to perform effort due to osteoarticular problems, recent respiratory infections, refusal to participate, or by the judgment of the team about the ability to perform effort safely. Participants with vestibular diseases and visual impairment were also excluded.

Risk stratification for cardiovascular events during exercise was performed based on the following self-reported cardiovascular risk factors: age, family history of cardiovascular disease, smoking status, hypertension, dyslipidemia, diabetes, obesity, and physical inactivity. Participants who had moderate-to-high cardiovascular risk were not included.

\section{Experimental procedures}

Evaluations for each participant were performed over two days with an interval of one week between them. The first day consisted of a general clinical evaluation, followed by anthropometry and cardiopulmonary exercise testing. Then, participants used a triaxial accelerometer above the dominant hip to assess the physical activity level for seven days. On the second day of evaluation, we evaluated body composition, static postural balance, peripheral muscle force, and endurance of the quadriceps femoris. These evaluations are described in detail below.

\section{- Anthropometry and body composition}

Height $(\mathrm{m})$ and body mass $(\mathrm{kg})$ were measured using a digital scale with a stadiometer (Toledo ${ }^{\circledR}$, São Paulo, Brazil). Then, we calculated the body mass index (BMI) in $\mathrm{kg} / \mathrm{m}^{2}$. We assessed body composition by bioelectrical impedance (310e BIODYNAMICS, Detroit, USA) and calculated lean and fat body mass as previously described ${ }^{13}$.

\section{- Peak $\mathrm{VO}_{2}$}

Participants were submitted to a symptom-limited CPET under a treadmill ramp protocol (ATL, Inbrasport, Brazil) to obtain peak oxygen uptake $\left(\mathrm{VO}_{2}\right)$, which was considered the average value of the $\mathrm{VO}_{2}(\mathrm{ml} / \mathrm{min} / \mathrm{kg})$ during the last $15 \mathrm{~s}$ of test ${ }^{14}$. We monitored $\mathrm{VO}_{2}$ throughout the test using a gas analyzer (Quark PFT, Cosmed, Pavona di Albano, Italy), and the heart rate by means of a 12 lead ECG. 


\section{- Physical activity level}

The physical activity level was evaluated using validated triaxial accelerometers as previously described ${ }^{15}$ (ActiGraph, MTI, Pensacola, FL). We carefully instructed participants to position the device above the dominant hip for seven consecutive days. We only analyzed data from participants who used the accelerometer for, at least, four valid days (e.g., at least, $10 \mathrm{~h}$ of monitoring) ${ }^{16}$. The threshold for moderate-to-vigorous was $>1,951 \mathrm{cpm}^{16}$. We considered physically inactive participants to be those with $<150 \mathrm{~min}-$ utes of moderate-to-vigorous physical activity ${ }^{17}$.

\section{- Static postural balance}

Postural balance was evaluated using kinetic data on the center of pressure (COP) dynamics on a force platform18 (400 BIOMEC; EMG System, Brazil). The frequency of data acquisition was $100 \mathrm{~Hz}$ and filtered using a low-pass cut-off of $0.5 \mathrm{~Hz}$. Participants were instructed to place one foot in front of the other (e.g., semi-tandem (ST) stance) and remain immobile with arms held alongside the body for 30s with and without visual information (Figure 1). Body sway was measured along with anteroposterior and mediolateral directions. We recorded the mean amplitude $(\mathrm{cm})$, median frequency $(\mathrm{Hz})$, and $\mathrm{COP}$ area $\left(\mathrm{cm}^{2}\right)$, and velocity $(\mathrm{cm} / \mathrm{s})$ for further analysis.

30s with eyes open

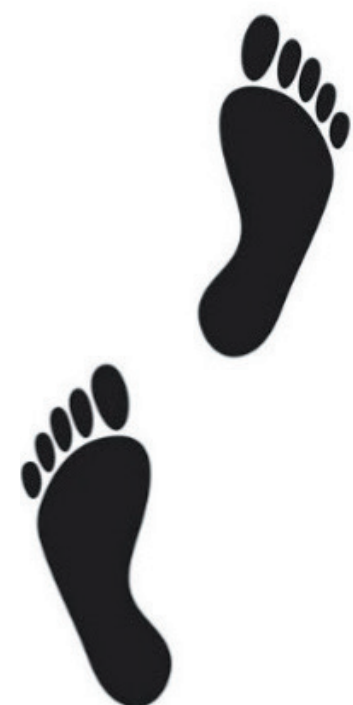

30s with eyes closed

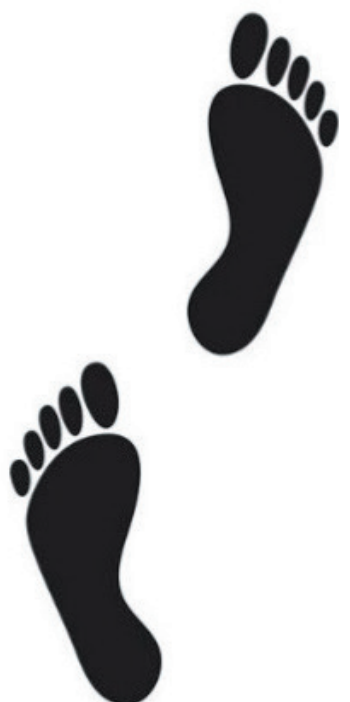

Figure 1. Illustration of foot position in semi-tandem stance.

\section{- Isokinetic muscle function}

After postural balance assessment, we measured muscle function of the quadriceps femoris on an isokinetic dynamometer ${ }^{19}$ (Biodex, Lumex Inc, USA). In a standard seated position with a hip angular position at $90^{\circ}$, the upper body and the lower limb to be assessed are fully fixed by strips. Equipment software properly corrects the influence of gravity and the weight of the limb to be evaluated during the test. The dynamometer calibration measures remained unchanged during the study. 
At first, we aligned the mechanical axis of rotation of the device to the rotational axis of the knee to apply three protocol tests to obtain isometric force as a measure of maximal voluntary contraction, peak torque (PT), and total work (TW) as a measure of muscle endurance.

In order to achieve isometric force, we instructed participants to perform a trial of five repetitions of isometric force recorded in $\mathrm{Nm}$ at $60^{\circ}$ for $5 \mathrm{~s}$ with rest periods of at least one minute. Then, the $\mathrm{PT}(\mathrm{Nm})$ of the concentric isokinetic knee extension was evaluated by a trial of five movements at $60 \%$ with range of motion from $90^{\circ}$ to $0^{\circ}$ of the knee flexion. After five minutes of rest, participants performed 30 repetitions at $300 \%$ s to record the TW $(\mathrm{kJ})$.

We applied these three protocol tests mentioned above to the quadriceps femoris of the dominant leg. Participants were verbally encouraged during the tests. The highest value in the isometric test was selected to compose the maximal voluntary contraction for adjustment of the electromyographic data. The isokinetic LMF was calculated by the difference between the first and last third of the 30-repetition test. We also used knee extension PT for further analysis.

\section{- Electromyography localized muscle fatigue}

We used surface electromyography (Miotec, Brazil) to assess LMF ${ }^{20}$. The EMG signals were collected during the isokinetic muscle endurance assessment of the dominant leg throughout 30 repetitions at $300 \% \mathrm{sg} /$ $\mathrm{AgCl}$ bipolar electrodes were positioned halfway between the anterior superior iliac spine and the superior border of the patella for monitoring rectus femoris muscle. We positioned the reference electrode on the spinous process of the seventh cervical vertebra.

We used an eight-channel biological signal acquisition module (MioTool wireless/USB ${ }^{\circledR}$ ) for registering the myoelectrical activity. The equipment was set at a 1000 -fold gain, $10 \mathrm{~Hz}$ high pass and $500 \mathrm{~Hz}$ low pass filters, a frequency of $2000 \mathrm{~Hz}$, and $120 \mathrm{~dB}$ reject module. We normalized the EMG signals using the maximal voluntary isometric contractions.

Then, we used the median frequency of the EMG power spectrum for the assessment of LMF during 30 contractions of the isokinetic muscle endurance test at $300 \%$ s. We excluded the first and the last five contractions in order to minimize possible instabilities in the acquisition of the electromyographic signals.

A visual inspection of electromyographic muscle fatigue was performed after Fast Fourier transformation to obtain their respective spectral power densities. We plotted the median frequency of the EMG signals against the 20 intermediate repetitions performed. We fit simple linear regression analyzes to evaluate the slope of the regression lines, which was considered a measure of the LMF for each participant. The more negative the coefficient, the higher the muscle fatigue.

\section{Statistical analysis}

Statistical analysis was performed using SPSS, version 23 (SPSS Inc., 
USA). Data were analyzed descriptively. Continuous variables were presented as mean \pm standard deviation or as median (interquartile range).

We evaluated the correlations between the continuous variables by the Pearson or Spearman coefficients, according to the data distribution. The association of electromyographic LMF in the maintenance of static postural balance was investigated in multiple linear regression models (enter method), adjusted for age, BMI, knee extension PT, and isokinetic LMF. We set the probability of alpha error at $5 \%$ for all statistical tests.

The sample size was estimated based on the relationship between the number of predictors desired for the multiple linear regression analyses and the minimum number of observations required, indicating at least 50 subjects for the elaboration of multiple linear models containing 4 to 5 variables (e.g., age, BMI, knee extension PT, and isokinetic LMF).

\section{RESULTS}

Our 51 participants were, on average, adult men with BMI slightly above average and mean body composition within normality (Table 1).

The median frequency of the EMG power spectrum of each participant was used for assessing LMF during 20 intermediate repetitions of the isokinetic muscle endurance test. After Fast Fourier transformation and visual inspection of fatigue, spectral power densities were obtained. Lastly, LMF was obtained for each participant as can be seen in Figure 2.

We observed significant weak-to-moderate correlations between postural balance variables and electromyographic LMF (Table 2). PT of isokinetic knee extension negatively correlated with mean amplitudes (e.g., anteroposterior and mediolateral) and COP area, but only in ST with eyes open. In turn, electromyographic LMF presented a positive significant correlation with mean amplitude in a mediolateral direction in ST with eyes open. We also found significant positive correlations between electromyographic LMF with mean amplitude in mediolateral direction and $\mathrm{COP}$ area and velocity in ST with eyes closed. Isokinetic LMF did not correlate with the postural balance variables.

PT of isokinetic knee extension, electromyographic and isokinetic LMF were significant predictors of postural balance (Table 3). PT predicted only mediolateral mean amplitude in ST stance with eyes open. Anteroposterior mean amplitude and median frequency with eyes open were predicted by isokinetic LFM, which also determined COP velocity in ST stance with eyes closed. Lastly, we found that electromyographic LMF was significant predictor for mediolateral mean amplitude for both eyes open and closed, as well as COP area and velocity respectively with eyes open and closed. Additionally, the multivariate models explained 0.08 a $32 \%$ of the variance of postural balance, mainly in mediolateral oscillations. 
Table 1. Characteristics of the studied sample $(n=51)$.

\begin{tabular}{|c|c|}
\hline Age (years) & $43 \pm 14.8$ \\
\hline Body mass index $\left(\mathrm{kg} / \mathrm{m}^{2}\right)$ & $26.9 \pm 5$ \\
\hline Peak VO ${ }_{2}(\mathrm{~mL} / \mathrm{min} / \mathrm{kg})$ & $39.5 \pm 10.6$ \\
\hline Fat body mass (\%) & $23.5 \pm 6.6$ \\
\hline Fat body mass (kg) & $19.7 \pm 8.7$ \\
\hline Lean body mass (\%) & $45.5 \pm 10.2$ \\
\hline Lean body mass (kg) & $61.3 \pm 38.1$ \\
\hline \multicolumn{2}{|l|}{ Isokinetic muscle function } \\
\hline Peak torque of the isokinetic knee extension at $60 \% \mathrm{~s}(\mathrm{~N} \cdot \mathrm{m})$ & $192.3 \pm 49.6$ \\
\hline Total work of the isokinetic knee extension at $300 \% \mathrm{~s}(\mathrm{~kJ})$ & $2467.2 \pm 676.6$ \\
\hline Peak torque of the isometric knee extension (N.m) & $237.9 \pm 58.3$ \\
\hline \multicolumn{2}{|l|}{ Surface electromyography } \\
\hline Localized muscle fatigue of rectus femoris & $-0.85(-1.13--0.78)$ \\
\hline \multicolumn{2}{|l|}{ Accelerometer-based physical activity } \\
\hline Moderate-to-vigorous physical activity (hour/week) & $5.3 \pm 0.2$ \\
\hline Moderate-to-vigorous physical activity (\%/week) & $5.9 \pm 0.3$ \\
\hline \multicolumn{2}{|l|}{ Semi-tandem stance with eyes open } \\
\hline Anteroposterior mean amplitude $(\mathrm{cm})$ & $2.11(1.73-2.64)$ \\
\hline Mediolateral mean amplitude (cm) & $1.81(1.31-2.37)$ \\
\hline Anteroposterior median frequency $(\mathrm{Hz})$ & $0.33(0.26-0.47)$ \\
\hline Mediolateral median frequency $(\mathrm{Hz})$ & $0.46(0.27-0.73)$ \\
\hline Center of pressure area $\left(\mathrm{cm}^{2}\right)$ & $1.97(1.45-3.14)$ \\
\hline Center of pressure anteroposterior mean velocity $(\mathrm{cm} / \mathrm{s})$ & $1.53(1.23-1.83)$ \\
\hline Center of pressure mediolateral mean velocity $(\mathrm{cm} / \mathrm{s})$ & $1.39(1.16-1.65)$ \\
\hline \multicolumn{2}{|l|}{ Semi-tandem stance with eyes closed } \\
\hline Anteroposterior mean amplitude $(\mathrm{cm})$ & $4.58(3.25-5.68)$ \\
\hline Mediolateral mean amplitude (cm) & $3.09(1.84-4.36)$ \\
\hline Anteroposterior median frequency $(\mathrm{Hz})$ & $0.40(0.26-0.53)$ \\
\hline Mediolateral median frequency $(\mathrm{Hz})$ & $0.66(0.40-0.80)$ \\
\hline Center of pressure area $\left(\mathrm{cm}^{2}\right)$ & $8.0(3.69-10.54)$ \\
\hline Center of pressure anteroposterior mean velocity $(\mathrm{cm} / \mathrm{s})$ & $3.06(2.14-3.50)$ \\
\hline Center of pressure mediolateral mean velocity $(\mathrm{cm} / \mathrm{s})$ & $2.29(1.77-1.39)$ \\
\hline
\end{tabular}

Note. Data presented as mean \pm SD and median (interquartile range).

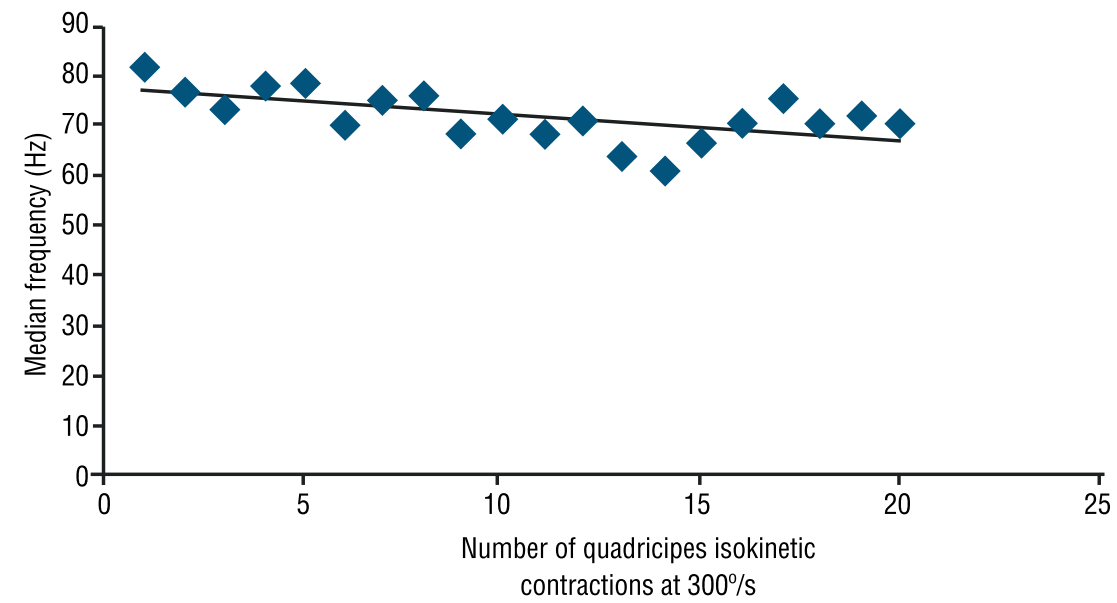

Figure 2. Simple linear regression analyzes with Fast Fourier transformation to obtain their respective spectral power densities to evaluate the slope (coefficients) of the tendency line of median frequency, which was considered a measure of the electromyographic localized muscle fatigue for each participant. 
Table 2. Correlations between variables of postural balance on a force platform in semi tandem stance and isokinetic muscle strength and localized muscle fatigue assessed by surface electromyography.

\begin{tabular}{|c|c|c|c|c|c|c|}
\hline \multirow[t]{2}{*}{ Postural balance variables } & \multicolumn{2}{|c|}{$\begin{array}{c}\text { Peak torque of the } \\
\text { isokinetic knee exten- } \\
\text { sion at } 60 \% \mathrm{~s}\end{array}$} & \multicolumn{2}{|c|}{$\begin{array}{l}\text { Electromyography } \\
\text { LMF }\end{array}$} & \multicolumn{2}{|c|}{$\begin{array}{l}\text { Isokinetic } \\
\text { LMF }\end{array}$} \\
\hline & $r$ & $p$ & $r$ & $\mathrm{p}$ & $r$ & $p$ \\
\hline \multicolumn{7}{|l|}{ Semi-tandem stance with eyes open } \\
\hline Anteroposterior mean amplitude (cm) & $-0.286^{*}$ & 0.042 & -0.153 & 0.285 & 0.133 & 0.362 \\
\hline Mediolateral mean amplitude (cm) & $-0.291^{*}$ & 0.038 & $0.367^{\star *}$ & 0.008 & 0.053 & 0.715 \\
\hline Anteroposterior median frequency $(\mathrm{Hz})$ & -0.062 & 0.668 & -0.020 & 0.888 & 0.267 & 0.064 \\
\hline Mediolateral median frequency $(\mathrm{Hz})$ & 0.117 & 0.415 & -0.180 & 0.205 & 0.273 & 0.057 \\
\hline Center of pressure area $\left(\mathrm{cm}^{2}\right)$ & $-0.331^{*}$ & 0.018 & 0.177 & 0.215 & 0.186 & 0.200 \\
\hline Center of pressure anteroposterior mean velocity $(\mathrm{cm} / \mathrm{s})$ & -0.087 & 0.554 & -0.033 & 0.822 & 0.089 & 0.551 \\
\hline Center of pressure mediolateral mean velocity $(\mathrm{cm} / \mathrm{s})$ & -0.107 & 0.465 & 0.198 & 0.173 & 0.006 & 0.967 \\
\hline \multicolumn{7}{|l|}{ Semi-tandem stance with eyes closed } \\
\hline Anteroposterior mean amplitude (cm) & -0.203 & 0.153 & 0.053 & 0.710 & 0.025 & 0.864 \\
\hline Mediolateral mean amplitude (cm) & -0.187 & 0.190 & $0.312^{*}$ & 0.026 & -0.008 & 0.959 \\
\hline Anteroposterior median frequency $(\mathrm{Hz})$ & 0.010 & 0.944 & -0.34 & 0.811 & 0.224 & 0.122 \\
\hline Mediolateral median frequency $(\mathrm{Hz})$ & 0.81 & 0.573 & -0.90 & 0.529 & 0.164 & 0.259 \\
\hline Center of pressure area $\left(\mathrm{cm}^{2}\right)$ & -0.191 & 0.180 & $0.279^{*}$ & 0.047 & 0.048 & 0.743 \\
\hline Center of pressure anteroposterior mean velocity $(\mathrm{cm} / \mathrm{s})$ & -0.208 & 0.151 & 0.096 & 0.510 & 0.211 & 0.154 \\
\hline Center of pressure mediolateral mean velocity $(\mathrm{cm} / \mathrm{s})$ & -0.243 & 0.92 & $0.333^{\star}$ & 0.019 & 0.025 & 0.869 \\
\hline
\end{tabular}

Note. LMF: localized muscle fatigue; ${ }^{*} p<0.05 ;{ }^{* *} p<0.01$

Table 3. Coefficients of the multiple linear regressions with variables of the postural balance on a force platform in semi tandem stance as the outcomes.

\begin{tabular}{|c|c|c|c|c|c|c|c|}
\hline \multirow{3}{*}{ Postural balance variables } & \multicolumn{6}{|c|}{ Muscle function assessment variables } & \multirow{3}{*}{$\mathrm{R}^{2}$} \\
\hline & \multicolumn{2}{|c|}{$\begin{array}{l}\text { Peak torque of the } \\
\text { isokinetic knee exten- } \\
\text { sion at } 60 \% \mathrm{~s}\end{array}$} & \multicolumn{2}{|c|}{$\begin{array}{l}\text { Electromyography } \\
\text { LMF }\end{array}$} & \multicolumn{2}{|c|}{ Isokinetic LMF } & \\
\hline & $\begin{array}{l}\text { Coefficient } \\
\text { (SE) }\end{array}$ & $p$ & $\begin{array}{l}\text { Coefficient } \\
\text { (SE) }\end{array}$ & $p$ & $\begin{array}{l}\text { Coefficient } \\
\text { (SE) }\end{array}$ & p & \\
\hline \multicolumn{8}{|l|}{ Semi-tandem stance with eyes open } \\
\hline Anteroposterior mean amplitude (cm) & $-0.004(0.003)$ & 0.119 & $-0.045(0.199)$ & 0.822 & $0.012(0.007)$ & 0.048 & 0.161 \\
\hline Mediolateral mean amplitude (cm) & $-0.006(0.003)$ & 0.032 & $0.578(0.204)$ & 0.007 & $0.005(0.007)$ & 0.469 & 0.311 \\
\hline Anteroposterior median frequency $(\mathrm{Hz})$ & $0.000(0.001)$ & 0.777 & $0.005(0.064)$ & 0.937 & $0.005(0.002)$ & 0.026 & 0.391 \\
\hline Mediolateral median frequency $(\mathrm{Hz})$ & $0.001(0.001)$ & 0.336 & $-0.069(0.085)$ & 0.421 & $0.004(0.003)$ & 0.133 & 0.181 \\
\hline Center of pressure area $\left(\mathrm{cm}^{2}\right)$ & $-0.008(0.005)$ & 0.079 & $0.707(0.350)$ & 0.049 & $0.019(0.012)$ & 0.113 & 0.131 \\
\hline Center of pressure anteroposterior mean velocity $(\mathrm{cm} / \mathrm{s})$ & $0.003(0.003)$ & 0.372 & $0.052(0.212)$ & 0.807 & $0.003(0.007)$ & 0.663 & 0.087 \\
\hline Center of pressure mediolateral mean velocity $(\mathrm{cm} / \mathrm{s})$ & $0.001(0.002)$ & 0.564 & $0.214(0.146)$ & 0.151 & $-0.001(0.005)$ & 0.770 & 0.134 \\
\hline \multicolumn{8}{|l|}{ Semi-tandem stance with eyes closed } \\
\hline Anteroposterior mean amplitude (cm) & $-0.001(0.006)$ & 0.839 & $0.387(0.483)$ & 0.427 & $0.011(0.016)$ & 0.516 & 0.124 \\
\hline Mediolateral mean amplitude (cm) & $0.003(0.007)$ & 0.679 & $1.379(0.534)$ & 0.013 & $0.008(0.018)$ & 0.680 & 0.323 \\
\hline Anteroposterior median frequency $(\mathrm{Hz})$ & $0.000(0.001)$ & 0.671 & $0.014(0.072)$ & 0.850 & $0.003(0.002)$ & 0.166 & 0.243 \\
\hline Mediolateral median frequency $(\mathrm{Hz})$ & $0.000(0.001)$ & 0.640 & $-0.040(0.079)$ & 0.619 & $0.003(0.003)$ & 0.258 & 0.047 \\
\hline Center of pressure area $\left(\mathrm{cm}^{2}\right)$ & $-0.003(0.029)$ & 0.913 & $3.663(2.219)$ & 0.106 & $0.098(0.075)$ & 0.201 & 0.143 \\
\hline Center of pressure anteroposterior mean velocity $(\mathrm{cm} / \mathrm{s})$ & $-0.006(0.006)$ & 0.313 & $0.393(0.449)$ & 0.387 & $0.028(0.015)$ & 0.049 & 0.159 \\
\hline Center of pressure mediolateral mean velocity $(\mathrm{cm} / \mathrm{s})$ & $-0.005(0.004)$ & 0.200 & $0.716(0.309)$ & 0.026 & $0.010(0.010)$ & 0.339 & 0.267 \\
\hline
\end{tabular}

Note. Data in bold represent the significant correlations $(\mathrm{p}<0.05)$. LMF: localized muscle fatigue, SE: standard error. Models adjusted for age (years), body mass index $\left(\mathrm{kg} / \mathrm{m}^{2}\right)$ and isokinetic LMF (\%). 


\section{DISCUSSION}

We investigated the association between electromyographic LMF of the rectus femoris and static postural balance in physically active adult men. Our findings showed that LMF was determinant for static postural balance in ST stance, especially in mediolateral oscillations. Additionally, this association remained significantly and independent regarding the isokinetic strength and endurance of the quadriceps femoris.

In the present study, we found an association between muscle strength and static postural balance, which agree with previous literature. A systematic review with meta-analysis described very similar results among 39 studies evaluating the correlation between strength and power of lower limb muscles and postural balance in children, adolescents, adults, and the elderly ${ }^{4}$. It would be rational to expect a consistent correlation. However, power generation during orthostatic posture is dependent on the task performed. Also, the influence of muscle strength/power on postural balance is age-dependent, being much more consistent in adolescents compared to adults and the elderly ${ }^{4}$.

The induction of muscle fatigue is common in almost all studies. A1though previous studies have greatly contributed to the understanding the muscle fatigue effect on postural balance, they present some limitations. The association between muscle fatigue and postural balance has been investigated by using high-intensity and short exercise protocols for fatigue induction ${ }^{7,8}$. Although several studies have evaluated running, walking, and cycling ${ }^{8}$, we induced fatigue through isokinetic fatigue protocol and assessed LMF by using EMG. It is also important to consider that we also did include postural balance assessment before and after induction of fatigue, which prevents us from reaching conclusions about the negative repercussion of post-exercise muscle fatigue on sports performance.

However, the methodology employed in the present study presents some advantages. First, we investigated the association between LMF and postural balance in the absence of ventilation effects, among other factors related to fatigue induction, since ventilation remains elevated until about $45 \mathrm{~s}$ after the task, jeopardizing postural balance ${ }^{8}$. Secondarily, electromyographic LMF as investigated in the present study has several advantages. The assessment of electromyographic LMF can be used as a way of assessing muscle function in addition to being non-invasive and having low $\operatorname{cost}^{21,22}$. For example, it can be widely used in rehabilitation as a tool to identify the limitation of muscle function. Further, it can be used in the diagnosis and prognosis of neuromuscular disorders, as well as in cases of peripheral neuropathy, among other applications. The use of electromyographic LMF would allow all of these evaluations to be carried out at a much lower cost compared to isokinetic dynamometry ${ }^{10,23}$. It is relevant to consider that the electromyography can be easily transported and used for evaluating other functional movements differently from the isokinetic dynamometer. 
The studies are also concentrated in the clinical setting with few physically active participants as volunteers. In turn, the present study involved physically active adults. We chose to study these participants because there is a substantial gap in the literature regarding these subjects, who are not athletes. As expected, the isokinetic and electromyographic LMF associated with postural balance, mainly with a mediolateral body sway. These findings related to body sway in mediolateral direction in a more challenging tasks (e.g., ST stance and without visual information) may be attributed to our sample characteristics.

Lower limb muscle fatigue has been previously described as a determinant of the greater COP oscillation in young individuals ${ }^{24}$ as well as for gait parameters changes and propensity for falls in the elderly ${ }^{25}$. Since our subjects were composed of adults, there may be greater adoption of postural strategies related mainly to the hip. In the absence of fatigue, young people prefer to adopt the ankle strategy while older people use the hip strategy to maintain balance ${ }^{26}$. Despite the age-related structural changes and strength decline, the evidence points to higher resistance to fatigue in elderly subjects compared to those younger in both isometric and dynamic contractions. However, the elderly showed a greater COP oscillation after fatigue induction protocols ${ }^{27}$. Together, the above evidence indicates that, with advancing age, maintaining balance after muscle fatigue in the elderly is more challenging than in young people ${ }^{27}$. Moreover, it has been suggested that older people balance using strategy more focused on the hip muscles in situations of fatigue ${ }^{26}$. Although fatigue was not induced before the assessment of postural balance in the present study, our results might be attributed to the strategies adopted to maintain postural balance, especially by the characteristics of our sample and the contribution of the proximal muscles and reorganization of coordination between the joints.

Our study conveniently involved adult $\mathrm{men}^{28}$, in whom cardiometabolic comorbidities are more prevalent. It is valid to consider that the increasing presence of cardiovascular risk factors contributes to impaired balance with aging probably due to the damage of the nervous system responsible for postural control ${ }^{29}$. However, it remains unclear whether postural instability in these individuals is associated with psychological factors or whether the worsening of balance is more substantial in fragile subjects.

The present study had limitations to consider. The small sample size limited the number of predictors of interest in the multivariate models and, consequently, the coefficient of determination. The evaluation of the rectus femoris muscle alone is also a weak point of our study since other segments (e.g., trunk, hip, and ankle) muscles are widely used in the research field. However, we chose the rectus femoris because it is a mixed muscle regarding muscle fiber types ${ }^{30}$, extensively used in daily living activities, and linked to several outcomes ${ }^{12}$.

To our knowledge, this is the first study to evaluate the association between LMF, and postural balance in physically active adult men. Also, we used accurate and sophisticated evaluations to obtain physical activity 
level, isokinetic and electromyographic LMF and postural balance, which strengthens our findings. Furthermore, our study evaluated the influence of rectus femoris fatigue on static postural balance without previous induction of fatigue, ruling out acute effects.

\section{CONCLUSION}

LMF plays a determinant role in the postural balance of physically active adult men. Our results suggest that muscular endurance training could be a rational strategy to improve the postural balance of physically active adults, allowing the improvement of performance, as well as the prevention of injuries and falls.

\section{COMPLIANCE WITH ETHICAL STANDARDS}

\section{Funding}

This study received financial support in the form of a research grant from the Fundação de Amparo à Pesquisa do Estado de São Paulo (FAPESP, São Paulo Research Foundation; Grant no. 2011/07282-6).

\section{Ethical approval}

Ethical approval was obtained from the local Human Research Ethics Committee - Federal University of São Paulo and the protocol (no. 0968/2016) was written in accordance with the standards set by the Declaration of Helsinki.

\section{Conflict of interest statement}

The authors have no conflict of interests to declare.

\section{Author contributions}

Conceived and designed the protocol: VZD, MMB. Performed the experiments: MMB, WOV, TLVPO. Analyzed the data: VZD, EFS, MMB. Wrote the paper: MMB, TLVPO, WOV, EFS, VZD.

\section{REFERENCES}

1. Bigland-Ritchie B, Rice CL, Garland SJ, Walsh ML. Task-dependent factors in fatigue of human voluntary contractions. Adv Exp Med Biol 1995;384:361-80.

2. Chaffin DB. Localized muscle fatigue - Definition and measurement. J Occup Med 1973;15(4):346-54.

3. Boyas S, Guével A. Neuromuscular fatigue in healthy muscle: Underlying factors and adaptation mechanisms. Ann Phys Rehabil Med 2011;54(2):88-108.

4. Muehlbauer T, Gollhofer A, Granacher U. Associations Between Measures of Balance and Lower-Extremity Muscle Strength/Power in Healthy Individuals Across the Lifespan: A Systematic Review and Meta-Analysis. Sports Med 2015;45(12):1671-92.

5. Hatton AL, Menant JC, Lord SR, Lo JCM, Sturnieks DL. The effect of lower limb muscle fatigue on obstacle negotiation during walking in older adults. Gait Posture 2013;37(4):506-10. 
6. Papa EV, Garg H, Dibble LE. Acute effects of muscle fatigue on anticipatory and reactive postural control in older individuals: A systematic review of the evidence. J Geriatr Phys Ther 2015;38(1):40-8.

7. Zemková E, Hamar D. Physiological mechanisms of post-exercise balance impairment. Sports Med 2014;44(4):437-48.

8. Zemková E, Hamar D. Postural sway after exercise bouts eliciting the same heart rate with different energy yield from anaerobic glycolysis. Med Sportiva 2003;7(4):E135-E139.

9. Kumar S, Fagarasanu M, Narayan Y, Prasad N. Measures of localized spinal muscle fatigue. Ergonomics 2006;49(11):1092-110.

10. De Luca CJ. Myoelectrical manifestations of localized muscular fatigue in humans. Crit Rev Biomed Eng 1984;11(4):251-79.

11. Hassani A, Patikas D, Bassa E, Hatzikotoulas K, Kellis E, Kotzamanidis C. Agonist and antagonist muscle activation during maximal and submaximal isokinetic fatigue tests of the knee extensors. J Electromyogr Kinesiol 2006;16(6):661-8.

12. Bordoni B, Varacallo M. Anatomy, Bony Pelvis and Lower Limb, Thigh Quadriceps Muscle. In: StatPearls. Treasure Island (FL): StatPearls Publishing; 2020.

13. Kyle UG, Bosaeus I, De Lorenzo AD, Deurenberg P, Elia M, Manuel Gómez J, et al. Bioelectrical impedance analysis-part II: utilization in clinical practice. Clin Nutr 2004;23(6):1430-53.

14. Hansen JE, Sue DY, Wasserman K. Predicted Values for Clinical Exercise Testing. Am Rev Respir Dis 1984;129(2P2):S49-55.

15. Freedson PS, Melanson E, Sirard J. Calibration of the Computer Science and Applications, Inc. accelerometer. Med Sci Sports Exerc 1998;30(5):777-81.

16. Migueles JH, Cadenas-Sanchez C, Ekelund U, Delisle Nyström C, Mora-Gonzalez J, Löf M, et al. Accelerometer Data Collection and Processing Criteria to Assess Physical Activity and Other Outcomes: A Systematic Review and Practical Considerations. Sport Med 2017;47(9):1821-45.

17. Garber CE, Blissmer B, Deschenes MR, Franklin BA, Lamonte MJ, Lee I-M, et al. American College of Sports Medicine position stand. Quantity and quality of exercise for developing and maintaining cardiorespiratory, musculoskeletal, and neuromotor fitness in apparently healthy adults: guidance for prescribing exercise. Med Sci Sports Exerc 2011;43(7):1334-59.

18. Paillard T, Noe F. Techniques and Methods for Testing the Postural Function in Healthy and Pathological Subjects. Biomed Res Int 2015;2015:891390.

19. Neder JA, Nery LE, Shinzato GT, Andrade MS, Peres C, Silva AC. Reference values for concentric knee isokinetic strength and power in nonathletic men and women from 20 to 80 years old. J Orthop Sports Phys Ther 1999;29(2):116-26.

20. Hermens HJ, Freriks B, Disselhorst-Klug C, Rau G. Development of recommendations for SEMG sensors and sensor placement procedures. J Electromyogr Kinesiol 2000;10(5):361-74.

21. Alves MA, Pinfildi CE, Neto LN, Lourenço RP, Azevedo PHSM, Dourado VZ. Acute effects of low-level laser therapy on physiologic and electromyographic responses to the cardiopulmonary exercise testing in healthy untrained adults. Lasers Med Sci 2014;29(6):1945-51.

22. Wang L, Wang Y, Ma A, Ma G, Ye Y, Li R, et al. A Comparative Study of EMG Indices in Muscle Fatigue Evaluation Based on Grey Relational Analysis during All-Out Cycling Exercise. Biomed Res Int 2018;2018:9341215.

23. Kienbacher T, Habenicht R, Starek C, Mair P, Wolf M, Paul B, et al. The potential use of spectral electromyographic fatigue as a screening and outcome monitoring tool of sarcopenic back muscle alterations. J Neuroeng Rehabil 2014;11(1):106.

24. Adlerton AK, Moritz U, Moe-Nilssen R. Forceplate and accelerometer measures for evaluating the effect of muscle fatigue on postural control during one-legged stance. Physiother Res Int 2003;8(4):187-99.

25. Parijat $P$, Lockhart TE. Effects of lower extremity muscle fatigue on the outcomes of slip-induced falls. Ergonomics 2008;51(12):1873-84. 
26. Paillard T, Noé F, Edeline O. Neuromuscular effects of superimposed and combined transcutaneous electrical stimulation with voluntary activity: A review. Ann Readapt Med Phys 2005;48(3):126-37.

27. Lin D, Nussbaum MA, Seol H, Singh NB, Madigan ML, Wojcik LA. Acute effects of localized muscle fatigue on postural control and patterns of recovery during upright stance: Influence of fatigue location and age. Eur J Appl Physiol 2009;106(3):425-34.

28. Ansdell P, Thomas K, Howatson G, Hunter S, Goodall S. Contraction intensity and sex differences in knee-extensor fatigability. J Electromyogr Kinesiol 2017;37:68-74.

29. Abate M, Di Iorio A, Pini B, Battaglini C, Di Nicola I, Foschini N, et al. Effects of hypertension on balance assessed by computerized posturography in the elderly. Arch Gerontol Geriatr 2016;49(1):113-7.

30. Johnson MA, Polgar J, Weightman D, Appleton D. Data on the distribution of fibre types in thirty-six human muscles. An autopsy study. J Neurol Sci 1973;18(1):111-29.

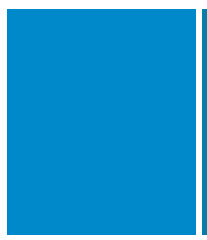

Corresponding author

Thatiane Lopes Valentim Di Paschoale Ostolin

136 Silva Jardim St, Santos, SP, 5513, BRA

CEP: $11015-020$ - tel.: 5513 3878-3803

Laboratory of Epidemiology and Human Movement,

Federal University of São Paulo, Santos, Brazil

Email: thati.ostolin@gmail.com 